\title{
Sumudu transform for some applications with constant proportional Caputo derivative
}

\author{
Esra Karataş Akgül ${ }^{1}$ and Ali Akgul ${ }^{1}$ \\ ${ }^{1}$ Siirt University
}

May 25, 2020

\begin{abstract}
In this study, we obtain the solutions of some interesting problems by Sumudu transform. We investigate the economic models based on market equilibrium with constant proportional Caputo derivative. We prove the efficiency of the Sumudu transform by some applications.
\end{abstract}

\section{Hosted file}

Paper Esra-Ali.pdf available at https://authorea.com/users/326118/articles/454005-sumudutransform-for-some-applications-with-constant-proportional-caputo-derivative 